\title{
Dual-Setting Calcium Phosphate Cement Modified with Ammonium Polyacrylate
}

\author{
*Luís Alberto dos Santos, †Raúl García Carrodeguas, \$Anselmo Ortega Boschi, and \\ *Antônio Celso Fonseca de Arruda \\ *Faculdade de Engenharia Mecânica, Universidade Estadual de Campinas, Campinas, SP, Brazil; \\ $\dagger$ Centro de Biomateriales, Universidad de La Habana, Cuba; and $\$$ Departamento de Engenharia de Materiais, \\ Universidade Federal de São Carlos, São Carlos, SP, Brazil
}

\begin{abstract}
Tricalcium phosphate bone cement, as formerly designed and developed by Driessens et al., consists of a powder composed by $\alpha$-tricalcium phosphate $(\alpha$-TCP) and hydroxyapatite (HA) seeds, and an aqueous solution of $\mathrm{Na}_{2} \mathrm{HPO}_{4}$ as mixing liquid. After mixing powder and liquid, $\alpha$-TCP dissolves into the liquid and calcium deficient hydroxyapatite (CDHA), more insoluble than the former, precipitates as an entanglement of crystals, which causes the setting and hardening of the cement. $\alpha$-TCP bone cement offers several advantages in comparison to calcium phosphate bioceramics and acrylic bone cements as bone graft and repairing material, like perfect adaptability to the defect size and shape, osteotransductibility, and absence of thermal effect during setting. The main handicap is its low mechanical strength. Therefore, approaching its mechanical strength to that of human bone could considerably extend its applications. In the present
\end{abstract}

work, an in situ polymerization system based on acrylamide (AA) and ammonium polyacrylate (PA) as liquid reducer was added to $\alpha$-TCP cement to increase its mechanical strength. The results showed that the addition of $20 \mathrm{wt} \%$ of acrylamide and $1 \mathrm{wt} \%$ AP to the liquid increased the compressive and tensile strength of $\alpha$-TCP bone cement by 149 and $69 \%$ (55 and $21 \mathrm{MPa}$ ), respectively. The improvement in mechanical strength seems to be caused by a decrease of porosity and the reinforcing effect of a polyacrylamide network coexisting with the entanglement of CDHA crystals. The studied additives do not affect the nature of the final product of the setting reaction, CDHA, but promote the reduction of its crystal size. Key Words: Calcium phosphate cement-Calcium phosphate- $\alpha$-tricalcium phosphate-Bioceramic-Biomaterial-Medical devices.
The term "Calcium Phosphate Cement" (CPC) was formerly introduced by Gruninger et al. (1), who state that this type of cement can be prepared by mixing a calcium phosphate salt with water or with an aqueous solution so that a paste is formed that can react at ambient or body temperatures to produce a precipitate containing one or more different calcium phosphates, and set by the entanglement of precipitated crystals.

CPCs offer several advantages over conventional calcium phosphate bioceramics and acrylic bone cement that permit their use as bone graft and sub-

Received December 2002.

Presented in part at the $2^{\text {nd }}$ Latin American Congress for Artificial Organs and Biomaterials, held December 2001, in Brazil.

Address correspondence and reprint requests to Dr. Luís Alberto dos Santos, Escola de Engenharia, Universidade Federal do Rio Grande do Sul, Av. Osvaldo Aranha, 99 sala 711, CEP 90035-190, Porto Alegre, RS, Brazil. E-mail: luis.santos@ufrgs.br stitute, including moldability; minimum bone cavity; direct in vivo insertion; in situ setting; optimum boneimplant contact; and biocompatibility and bioactivity.

Moreover, several substances such as antibiotics, antitumoral, or antinflammatory drugs can be easily added to CPCs generating drug delivery systems (2). The main disadvantage of CPCs is their low mechanical resistance, which in the best of cases is equal to that of trabecular bone, or to $20 \%$ of the cortical bone. The literature does not contain sound studies related to the increase of the mechanical strength of CPCs. CPCs with mechanical resistance close to that of human bones would have a considerably broader field of clinical applications, currently limited to some orthopedic and maxillofacial procedures.

Driessens et al. developed a kind of CPC based on $\alpha$-tricalcium phosphate $(\alpha-\mathrm{TCP})$ and hydroxyapatite (HA) seeds, and an aqueous solution of $\mathrm{Na}_{2} \mathrm{HPO}_{4}$ as mixing liquid. After mixing powder and liquid, $\alpha$ - 
TCP dissolves into the liquid and calcium deficient hydroxyapatite (CDHA), more insoluble than the former, precipitates as an entanglement of crystals, which causes the set and hardening of the cement. The setting reaction occurring in this CPC, termed Biocement $\mathrm{H}$ by its developers, is presented in Eq. 1 (3-5).

$$
3 \alpha-\mathrm{Ca}_{3}\left(\mathrm{PO}_{4}\right)_{2(\mathrm{~s})}+\mathrm{H}_{2} \mathrm{O} \rightarrow \mathrm{Ca}_{9}\left(\mathrm{HPO}_{4}\right)\left(\mathrm{PO}_{4}\right)_{5} \mathrm{OH}_{(\mathrm{s})}
$$

According to Ginebra et al. (5), the initial and final setting times of Biocement $\mathrm{H}$ were 6 and $15 \mathrm{~min}$ at $37^{\circ} \mathrm{C}$, respectively and its ultimate compressive strength $24 \mathrm{~h}$ after mixing was $35 \pm 5 \mathrm{MPa}$ at $37^{\circ} \mathrm{C}$.

However, these values of setting times and strength are difficult to reproduce for $\alpha$-TCP-based CPCs because of the variability of $\alpha$-TCP phosphate properties from different sources. Factors like mean particle size and distribution, specific surface area, wettability, and phase impurities markedly influence the properties of the resulting cement.

In a previous report $(6,7)$, the authors showed that by incorporating an in situ polymerization system to $\alpha$-TCP CPC, the shortcomings related to the $\alpha$-TCP powder can be overcome. The resulting hybrid system was named dual-setting CPC.

The objective of this work was to study the influence of the addition of an in situ polymerization system based on acrylamide, and ammonium polyacrylate as water reducer on the properties of $\alpha$-TCP cement.

\section{EXPERIMENTAL PROCEDURES}

\section{Preparation of the cement}

Powder: $\alpha$-TCP was prepared by reacting $\mathrm{CaCO}_{3}$ and $\gamma-\mathrm{Ca}_{2} \mathrm{P}_{2} \mathrm{O}_{7}$ in equimolar amounts (8). The reagents were dry ball milled (polyethylene jar, $\mathrm{ZrO}_{2}$ balls) and calcined at $1,300^{\circ} \mathrm{C}$ for 15 hours, followed by quenching on a stainless steel plate (9). The product was wet milled (anhydrous ethanol). The dis- tribution of particle sizes was determined by using a Sedigraph-Micromeritics 5100, with isopropanol as the dispersing agent. Ammonium persulfate (AP), $0.01 \mathrm{wt} \%$, was added to $\alpha-\mathrm{TCP}$ as polymerization initiator in dual-setting formulations.

Mixing Liquid: A $2.5 \mathrm{wt} / \mathrm{vol}-\% \mathrm{Na}_{2} \mathrm{HPO} 4$ solution was used as mixing liquid. Variable amounts of acrylamide (AA), $0.5 \mathrm{wt} / \mathrm{vol}-\%$ of $\mathrm{N}, \mathrm{N}^{\prime}$ methylenebisacrylamide (MBAM), $0.25 \mathrm{wt} / \mathrm{vol}-\%$ of $\mathrm{N}, \mathrm{N}, \mathrm{N}^{\prime}, \mathrm{N}^{\prime}$-tetramethylethylenediamide (TEMED), and $1 \mathrm{wt} / \mathrm{vol}-\%$ ammonium polyacrylate (PA) were added to the $\mathrm{Na}_{2} \mathrm{HPO}_{4}$ solution in dual-setting formulations.

The compositions of the cement formulations studied in this work are shown in Table 1.

\section{X-ray diffraction (XRD) analysis}

$\alpha$-TCP starting powder and set cements were submitted to qualitative and quantitative $\mathrm{x}$-ray diffraction analysis, using an x-ray diffractometer D 5000 (Siemens, Karlshüre, Germany) with $\mathrm{CuK}_{\alpha}$ Ni-filtered radiation, and target voltage and current of $40 \mathrm{kV}$ and $40 \mathrm{~mA}$. A scan rate of $2^{\circ}(2 \theta) / \mathrm{min}$ was employed for qualitative analysis. The internal standard method was used in quantitative analysis (10), and step scanning with intervals of $0.017^{\circ}$ and counting time of 2 seconds. Diffraction lines (0210) for $\beta$-TCP (internal standard) (11), (211) for HA, and (170) for $\alpha$-TCP, were used to estimate the phase contents.

\section{Mechanical strength measurement}

Five samples measuring $6 \mathrm{~mm}$ in diameter and $12 \mathrm{~mm}$ in height for tests of compressive strength and cylinders of $20 \mathrm{~mm}$ diameter and $10 \mathrm{~mm}$ height for tests of tensile (diametral compressive) strength were prepared from each composition, using a stainless steel mold. The samples were maintained at $100 \%$ relative humidity for 24 hours, and then placed in polystyrene flasks with simulated body fluid (SBF) with ion concentrations $\left(\mathrm{Na}^{+} 142.0, \mathrm{~K}^{+} 5.0, \mathrm{Ca}^{2+}\right.$

TABLE 1. Cement compositions studied in this work

\begin{tabular}{|c|c|c|c|}
\hline Number & Powder & Liquid & $\mathrm{L} / \mathrm{P}$ \\
\hline I & $100 \% \alpha-\mathrm{TCP}$ & $2.5 \% \mathrm{Na}_{2} \mathrm{HPO}_{4}$ & $0.32 \mathrm{~mL} / \mathrm{g}$ \\
\hline II & $100 \% \alpha$-TCP $; 0.01 \%$ AP & $\begin{array}{l}5 \% \text { AA; } 0.5 \% \text { MBAM; } 0.25 \% \\
\text { TEMED; } 2.5 \% \mathrm{Na}_{2} \mathrm{HPO}_{4} ; 1 \% \\
\text { PA }\end{array}$ & $0.30 \mathrm{~mL} / \mathrm{g}$ \\
\hline III & $100 \% \alpha-\mathrm{TCP} ; 0.01 \%$ AP & $\begin{array}{l}10 \% \text { AA; } 0.5 \% \text { MBAM; } 0.25 \% \\
\text { TEMED; } 2.5 \% \mathrm{Na}_{2} \mathrm{HPO}_{4} ; 1 \% \\
\text { PA }\end{array}$ & $0.30 \mathrm{~mL} / \mathrm{g}$ \\
\hline IV & $100 \% \alpha-\mathrm{TCP} ; 0.01 \%$ AP & $\begin{array}{l}20 \% \text { AA; } 0.5 \% \text { MBAM; } 0.25 \% \\
\text { TEMED; } 2.5 \% \mathrm{Na}_{2} \mathrm{HPO}_{4} ; 1 \% \\
\text { PA }\end{array}$ & $0.30 \mathrm{~mL} / \mathrm{g}$ \\
\hline
\end{tabular}


2.5, $\mathrm{Mg}^{2+} 1.5, \mathrm{Cl}^{-}$148.8, $\mathrm{HPO}_{4}^{-}$1.0, $\mathrm{HCO}_{3}^{2-} 4.2, \mathrm{SO}_{4}^{2-}$ $0.5 \mathrm{mmol} / \mathrm{L}$ ) and maintained at $36.5 \pm 0.5^{\circ} \mathrm{C}$ for 24 hours or 7 days (liquid/solid volumetric ratio $=50$ ). The compressive and tensile strengths were measured in a Universal Testing Machine (model TTDML Instron Corporation, Canton, MA, U.S.A.), using 5 replicas, at a loading rate of $1 \mathrm{~mm} / \mathrm{min}$.

\section{Scanning electron microscopy (SEM)}

Small pieces of the samples were recovered after compressive strength test and they were goldcoated. The fracture surface was examined in the scanning electron microscope (Philips XL30 TMP D6615).

\section{Fourier transform-infrared spectroscopy (FTIR)}

The cement samples were powdered in agate mortar under $150 \mu \mathrm{m}$ mesh. The sample $(0.1 \mathrm{wt} \%)$ was mixed with $\mathrm{KBr}$ and pressed into disks for infrared spectroscopy. The analysis was carried out in a Bomen 102 spectrophotometer in the range 4,000$400 \mathrm{~cm}^{-1}$.

\section{Porosity measurements}

The porosity was measured by the Archimedes method. The immersion liquid was kerosene.

\section{RESULTS AND DISCUSSIONS}

\section{$\alpha$-TCP particle size}

The particle size distribution of $\alpha$-TCP ranged from 25 to $2 \mu \mathrm{m}$ with an average diameter of $8 \mu \mathrm{m}$, similarly to other $\alpha$-TCP powders employed for preparing Biocement $\mathrm{H}(11,12)$. The coincidence in particle size distribution of the starting $\alpha$-TCP powder, and the fact that particle size distribution of the powder is decisive for the liquid/powder ratio needed to obtain a paste with adequate consistence, explain the same minimum liquid/powder ratio for formulation I in Table $1(0.32 \mathrm{~mL} / \mathrm{g})$ as that reported for similar cements $(11,12)$.

\section{X-ray diffraction}

The $\alpha$-TCP obtained contained $3 \mathrm{wt} \%$ of $\beta$-TCP impurity, as determined by quantitative $\mathrm{x}$-ray diffraction analyses. The $\mathrm{x}$-ray pattern is presented in Fig. 1A. Several authors have previously reported the presence of $\beta$-TCP impurity in $\alpha$-TCP at levels up to $15 \mathrm{wt} \%$ (11-15). Reports on the synthesis of pure $\alpha-$ TCP have not been found in the literature.

Figure 1B shows the $\mathrm{x}$-ray diffractograms of the cements containing poly(acrylamide) (II, III, and IV) and unmodified (I). The addition of ammonium poly(acrylate) and increasing contents of acrylamide
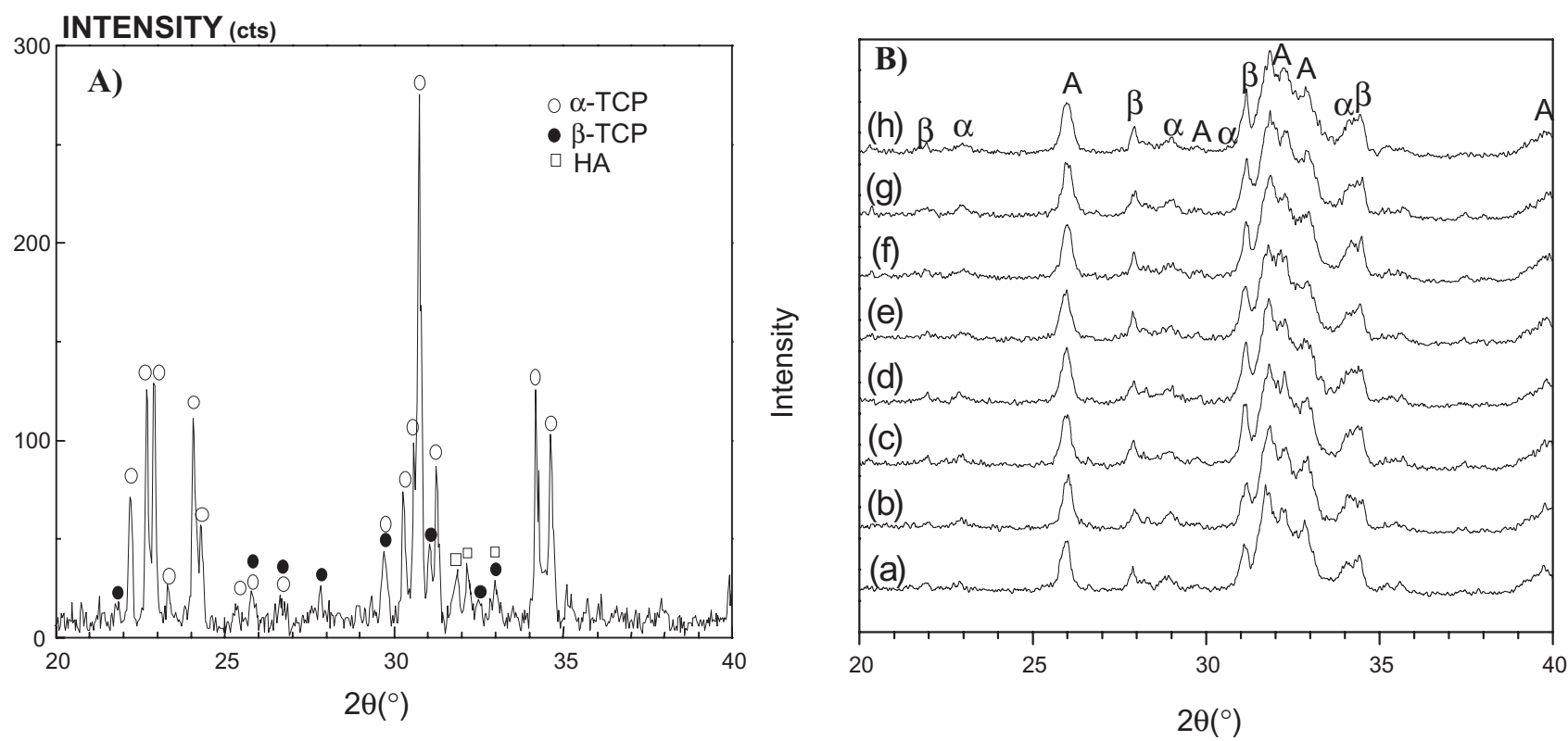

FIG. 1. A) X-ray diffraction pattern of the starting $\alpha$-TCP powder is shown. B) X-ray diffraction patterns of the cement compositions after immersion in SBF at $36.5^{\circ} \mathrm{C}$ are shown. Illustrated are (a) composition I immersed for 24 hours; (b) composition I immersed for 7 days; (c) composition II immersed for 24 hours; (d) composition II immersed for 7 days; (e) composition III immersed for 24 hours; (f) composition III immersed for 7 days; (g) composition IV immersed for 24 hours; (h) composition IV immersed for 7 days. ( $\alpha$ ) $\alpha$-TCP; ( $\beta$ ) $\beta$-TCP; (A) hydroxyapatite. 

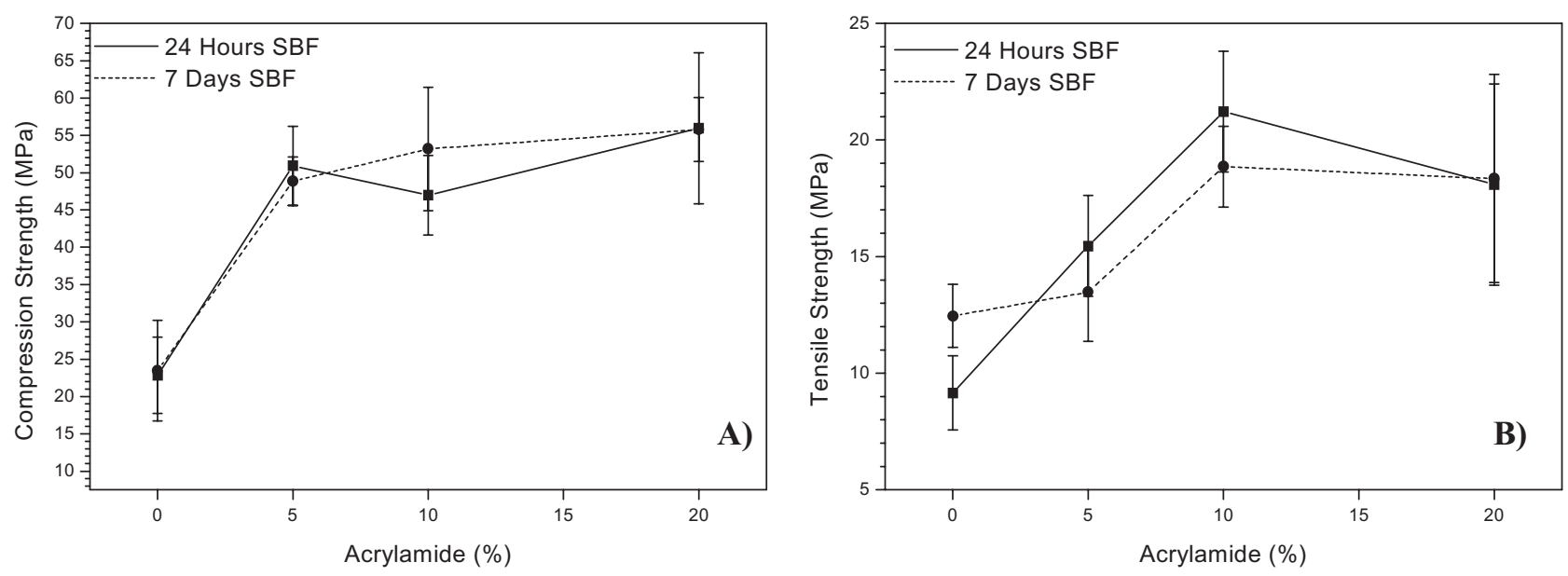

FIG. 2. A) Compressive strength of the compositions containing AA and PA, after 24 hours and 7 days of immersion in SBF, is shown. B) Tensile strength of the compositions containing AA and PA, after 24 hours and 7 days of immersion in SBF, is shown.

did not interfere in the final product of the reaction; apatite (JCPDF 9-432) was the only new crystalline phase originated by the setting of the cements. Intensities of $\beta$-TCP peaks practically do not vary from unreacted cement powder to set cement, confirming previous reports on the inertness or low reactivity of $\beta$-TCP in this system (11).

\section{Mechanical strength}

Besides studying the effect of the addition of ammonium polyacrylate (PA), it was aimed to determine the amount of AA in the cement composition rendering the maximum mechanical strength.

The presence of AA and the other organic additives in the mixing liquid increased neither its viscosity nor that of cement paste. This made it possible to reduce the liquid/powder ratio in modified cements in regard to unmodified cement. The combined use of PA and the polymerization system based on AA produced a significant increase in mechanical strength. The highest average compressive strength corresponded to composition IV, containing $20 \mathrm{wt} /$ vol- $\%$ of AA in the liquid (Fig. 2A). The compressive strength obtained for this composition was $55 \mathrm{MPa}, 149 \%$ of the value corresponding to unmodified cement (formulation I) for both periods of immersion in SBF. This compressive strength value is not too far from the minimum limit required by ASTM F451-86 and ISO 5833 standards for poly(methyl methacrylate)-based bone cements (70 MPa). Chow et al. (16) have reported a slightly higher compressive strength for a CPC. They reached an increase in compressive strength from 36.0 to 66.1 MPa by using molding under constant pressure, and special mold design and removing technique.
Tensile strength (Fig. 2B) also increased significantly for modified compositions. The highest strength, $21.2 \mathrm{MPa}$, corresponded to composition III, containing $10 \mathrm{wt} / \mathrm{vol}-\%$ of AA, after being immersed for 24 hours in $\mathrm{SBF}$ at $36.5^{\circ} \mathrm{C}$. This figure represents an increase of $69.6 \%$ when compared to the largest value of tensile strength of unmodified composition I, $12.5 \mathrm{MPa}$, after being immersed in SBF for 7 days. It can also be noticed that compressive and tensile strengths of the AA containing cements do not significantly vary with time of immersion in SBF.

Other polymeric additives have been tested for modifying CPCs, among them atelocollagen (17), gelatin, poly(vinyl alcohol), poly(acrylic acid), poly (acrylic-co-itaconic acid) (18), poly(methylvinylmaleic ether) acid (19), carboxymethyl cellulose, hydroxypropylmethyl cellulose, chitosan lactate and acetate (20), pectin (21), and dextran sulfate (22). Contrary to the results obtained in the present work, almost all additives decreased or did not affect the strength. Some acid additives increased the strength of cements via salt formation. In all cases partial or total inhibition of apatite formation was observed.

Differently, the polymerization system here employed, besides strengthening the cement, does not significantly interfere with the evolution of apatite during the setting of the cement.

The increase in mechanical strength of the cements is directly linked to reduction of porosity (Fig. 3). It is well known that ultimate strength $(\sigma)$ of a ceramic material decreases exponentially with the pore volume $(\mathrm{P})$ according to Eq. 2, where $\mathrm{n}$ is a constant, whose value ranges from 4 to 7 . 


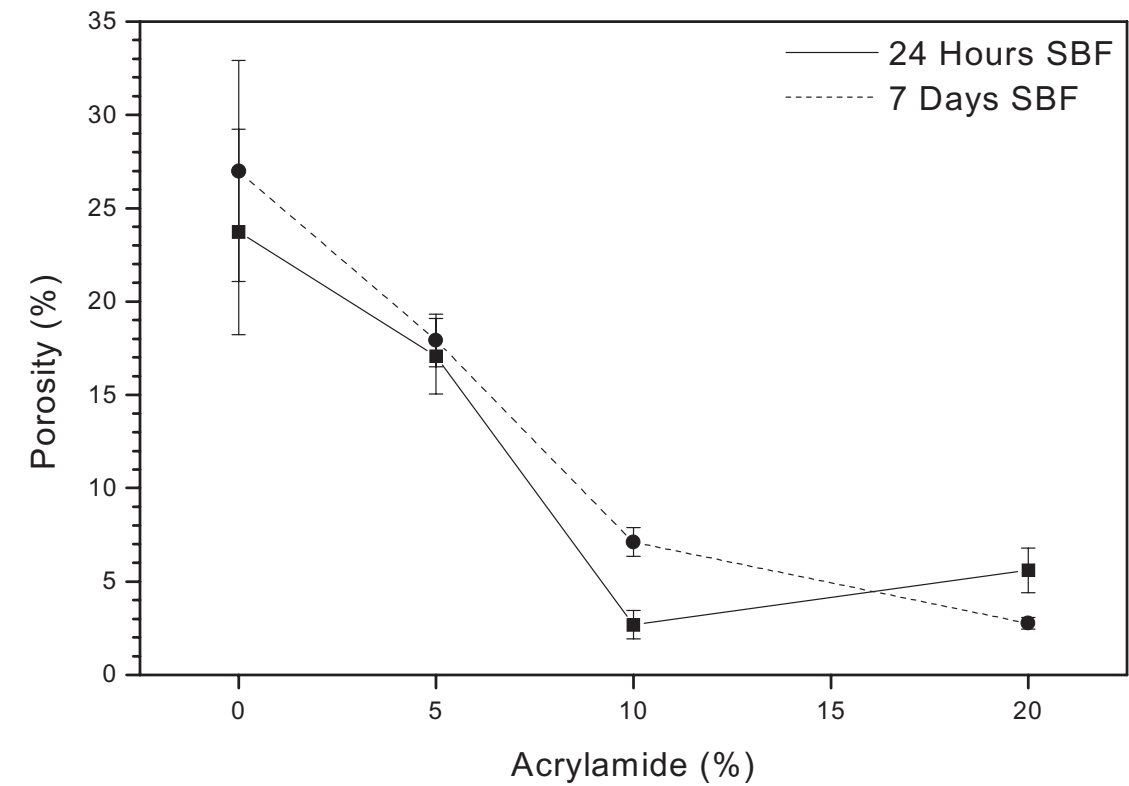

FIG. 3. Apparent porosity of the compositions containing $A A$ and $P A$, after 24 hours and 7 days of immersion in SBF, is shown.

$$
\sigma=\sigma_{\mathrm{o}} \exp (-\mathrm{nP})
$$

However, the increase of mechanical strength does not seem to be only a consequence of the decrease of porosity. It is also related to the increase of the amount of poly(acrylamide) hydrogel.

The reduction of porosity, and the consequent increase in compressive and tensile strengths, is attributed to the addition of PA, which deflocculates the $\alpha$-TCP powder and improves its wettability, thus reducing the amount of liquid needed to obtain a paste with cement consistency. According to previous results, the use of the in situ polymerization system alone did not allow reducing apparent porosity below $30 \%(6,7)$.

\section{Infrared spectroscopy (FTIR)}

Figure 4 shows the infrared spectra of the cement compositions containing poly(acrylamide) (II, III, and IV) and unmodified (I). The following absorption bands were detected: 471,563 , and $660 \mathrm{~cm}^{-1}$, all related to $\mathrm{P}-\mathrm{O}$ bond or to $\mathrm{PO}_{4}$ groups; $873 \mathrm{~cm}^{-1}$ regarding $\mathrm{C}-\mathrm{O}$ bond of $\mathrm{CO}_{3}$ group; $961 \mathrm{~cm}^{-1}$ assigned to stretching of $\mathrm{P}-\mathrm{OH}$ bond in $\mathrm{HPO}_{4}$ groups; $1.030 \mathrm{~cm}^{-1}$, $\mathrm{P}-\mathrm{O}$ stretching in $\mathrm{PO}_{4}$ groups; 1.454 and $1.414 \mathrm{~cm}^{-1}$, $\mathrm{C}-\mathrm{O}$ stretching in $\mathrm{CO}_{3}$ groups of carbonated hydroxyapatite; $1.640 \mathrm{~cm}^{-1}$, amide I band, originated by axial deformation of $\mathrm{C}=\mathrm{O}$ (overlap); $2.960 \mathrm{~cm}^{-1}$ axial deformation of aliphatic C-H; $3.580 \mathrm{~cm}^{-1}$, O-H stretching of hydroxyl groups; and 3.700 to $3.000 \mathrm{~cm}^{-1}$ due to O-H stretching of adsorbed $\mathrm{H}_{2} \mathrm{O}$.

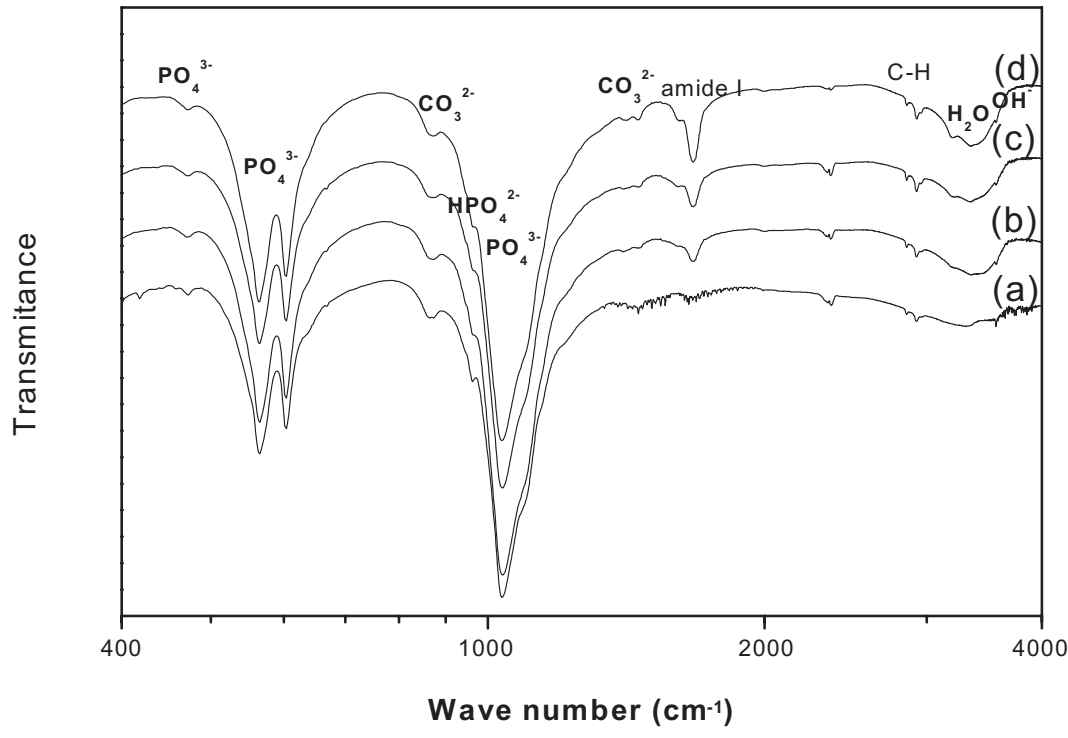

FIG. 4. Infrared spectra after immersion in SBF at $36.5^{\circ} \mathrm{C}$ for 7 days are shown. Shown are (a) composition I; (b) composition II; (c) composition III; and (d) composition IV. 



FIG. 5. Shown are SEM images of fracture surface of: A) composition I, B) composition II, C) composition III, and D) composition IV, after 7 days of immersion in SBF at $36.5^{\circ} \mathrm{C}$.

It was observed that the addition of growing amounts of AA and PA did not interfere with the formation of CDHA, as evidenced by the presence of bands at $961 \mathrm{~cm}^{-1}$, typical of $\mathrm{HPO}_{4}^{2-}$ group in CDHA (23). $\mathrm{CO}_{3}^{2-}$ bands at 1454 and $873 \mathrm{~cm}^{-1}$ demonstrated that the CDHA is also partially carbonated. The source of $\mathrm{CO}_{3}^{2-}$ ions is probably the SBF employed for incubating the samples at $36.5^{\circ} \mathrm{C}$. An enlargement of the bands characteristic of poly(acrylamide) $\left(1.640 \mathrm{~cm}^{-1}\right.$ and $\left.2.960 \mathrm{~cm}^{-1}\right)$ and adsorbed $\mathrm{H}_{2} \mathrm{O}(3.000$ to $3.700 \mathrm{~cm}^{-1}$ and $1.615 \mathrm{~cm}^{-1}$ ) with the increase of AA content was also noticed. This behavior is attributed to the increase of the amount of highly hydrophilic poly(acrylamide) hydrogel in the cement.

\section{Scanning electron microscopy (SEM)}

Figure 5 shows the SEM micrographs of the surface of fracture of the modified (II, III, and IV) and unmodified (I) cements after immersion for 7 days in SBF. CDHA crystals with petaloid shape that form an interlocked crystalline network can be observed. This crystalline entanglement is responsible for the mechanical strength of the cement. Similar structures have been described for $\alpha$-TCP cements (3-5). The addition of the polymerization system and of the liquid reducer promoted the reduction of the crystal size of the CDHA precipitate. The reduction of the CDHA crystal size is also observed when pastes of CPCs are submitted to high pressures 
and it is believed to contribute to reduce porosity and to increase mechanical strength. The reduction in crystal size is a consequence of a minor amount of liquid around the particles, leading to contact between precipitated CDHA crystals that hinder their further growth (24).

\section{CONCLUSIONS}

The addition of PA to compositions of CPC containing increasing amounts of AA evokes the following effects: The addition of PA allowed the reduction of the amount of liquid, necessary for obtaining a cement paste with an appropriate consistency from 0.32 to $0.30 \mathrm{~mL} / \mathrm{g}$. Second, the reduction of the amount of liquid and the deflocculating effect of PA promoted the reduction of the apparent porosity for the dual-setting CPC, producing an increase of up to $149 \%$ (55 MPa) in compressive strength and up to $69 \%(21.2 \mathrm{MPa})$ in tensile strength, when compared to the values of the unmodified CPC. Third, the addition of PA and increasing amounts of AA to the cement composition did not interfere in the final product of the setting reaction, CDHA, but promoted the reduction of its crystal size.

Acknowledgments: Our acknowledgments go to FAPESP (Foundation for Research Support of the São Paulo State, Brazil), Grants Nos. 98/11691-2 and 98/00563-3.

\section{REFERENCES}

1. Gruninger SE, Siew C, Chow LC, Oyoung A, Tsao NK, Brown WE. Evaluation of the biocompatibility of a new calcium phosphate setting cement. J Dent Res 1984;63:200.

2. Yu D, Wong J, Matsuda Y, Fox JL, Higuchi WI, Otsuka M. Selfsetting hydroxyapatite cement: A novel skeletal drug delivery system for antibiotics. J Pharm Sci 1992;81(6):529-31.

3. Ginebra MP, Boltong MG, Fernández E, Planell JA, Driessens FCM. Effect of various additives and temperature on some properties of an apatitic calcium phosphate cement. J Mater Sci Mater Med 1995;6:612-6.

4. Ginebra MP, Fernández E, Driessens FCM, Planell JA. The effect of $\mathrm{Na}_{2} \mathrm{HPO}_{4}$ addition on the setting reaction kinetics of an $\alpha$-TCP cement. In: LeGeros RZ, LeGeros JP, eds., Bioceramics Vol. 11 (Proceedings of the $11^{\text {th }}$ International Symposium on Ceramics in Medicine), New York: World Scientific Publishing Co. Pte. Ltd., 1998:243-6.

5. Ginebra MP, Fernández E, Driessens FCM, Boltong MG, Muntasell J, Font J, Planell JA. The effects of temperature on the behaviour of an apatitic calcium phosphate cement. $J$ Mater Sci Mater Med 1995;6:857-60.
6. Santos LA, Oliveira LC, Rigo ECS, Carrodéguas RG, Boschi AO, Arruda ACF. Influence of polymeric additives on the mechanical properties of $\alpha$-tricalcium phosphate cement. Bone 1999;25(2):99S-102S.

7. Carrodéguas RG, Oliveira LC, Santos LA, Rigo ECS, Boschi AO, Mondéjar SP. Cementos de $\alpha$-fosfato tricálcico de fraguado doble. Revista CNIC. Serie Ciencias Químicas (Cuba) 1999;30(3):153-8.

8. Driessens FCM, Fernández E, Ginebra MP, Boltong MG, Planell JA. Calcium phosphates and ceramic bone cements vs. acrylic cements. Anal Quim Int 1997;93:S38-S43.

9. Monma H, Goto M, Kohmura T. Effect of additives on hydration and hardness of tricalcium phosphate. Gypsum and Lime 1984:188:11-6.

10. Jenkins R, Vries JL. An introduction to X-ray powder diffractometry. N. V. Philips Gloeilampenfabrieken-EindhovenHolanda, 1971.

11. Ginebra MP, Fernández E, De Maeyer EAP, Verbeeck RMH, Boltong MG, Ginebra J, Driessens FCM, Planell JA. Setting reaction and hardening of an apatitic calcium phosphate cement. J Dent Res 1997;76(4):905-12.

12. Fernández E, Ginebra MP, Boltong MG, Verbeeck RMH, Planell JA. Kinetic study of the setting reaction of a calcium phosphate bone cement. J Biomed Mater Res 1996;32:367-74.

13. Bermúdez O, Boltong MG, Driessens FCM, Planell JÁ. Development of an octacalcium phosphate cement. J Mater Sci Mater Med 1994;5:144-6.

14. Tampieri A, Celotti G, Szontagh F, Landi E. Sintering and characterization of HA and TCP bioceramics with control of their strength and phase purity. J Mater Sci Mater Med 1997;8:29-37.

15. Famery R, Richard N, Boch P. Preparation of $\alpha$ - and $\beta$ tricalcium phosphate ceramics with and without magnesium addition. Ceramics International 1994;20:327-36.

16. Chow LC, Hirayama S, Takagi S, Parry E. Diametral tensile strength and compressive strength of a calcium phosphate cement: effect of applied pressure. J Biomed Mater Res 2000;53:511-7.

17. Miyamoto $\mathrm{Y}$, Ishikawa $\mathrm{K}$, Takechi $\mathrm{M}$, Toh $\mathrm{T}$, Yuasa $\mathrm{T}$, Nagayama M, Suzuki K. Basic properties of calcium phosphate cement containing atelocollagen in its liquid or powder phases. Biomaterials 1998;19:707-15.

18. Miyazaki K, Horibe T, Antonucci JM, Takagi S, Chow LC. Polymeric calcium phosphate cements: analysis of reaction products and properties. Dent Mater 1993;9:41-5.

19. Matsuya Y, Antonucci JM, Matsuya S, Takagi S, Chow LC. Polymeric calcium phosphate cements derived from poly(methyl vinyl ether-maleic acid). Dent Mater 1996;12:2-7.

20. Cherng A, Takagi S, Chow LC. Effects of hxydroxypropyl methylcellulose and other gelling agents on the handling properties of calcium phosphate cement. J Biomed Mater Res 1997:35:273-7.

21. Sawamura T, Hattori M. Calcium phosphate composition and a setting solution therefore. US Patent 5,980,625, November 9, 1999.

22. Sawamura T, Hattori M, Okuyama M. Calcium phosphate cement and calcium phosphate cement composition. US Patent 5,993,535, November 30, 1999.

23. LeGeros RZ. Calcium phosphates in oral biology and medicine monography in oral science - Vol. 15. Switzerland: S. Karger, 1991.

24. Ishikawa K, Asaoka K. Estimation of ideal mechanical strength and critical porosity of calcium phosphate cement. $J$ Biomed Mater Res 1995;29:1537-43. 